\title{
SOCIALIZANDO UM INSTRUMENTO DE AUTOAVALIAÇÃO DE AULAS REMOTAS NA PÓS-GRADUAÇÃO
}

\author{
SOCIALIZACIÓN DE UN CUESTIONARIO DE AUTOEVALUACIÓN PARA \\ ENSEÑANZA REMOTA EN LA POSTGRADUACIÓN
}

\author{
SOCIALIZING A SELF-EVALUATION TOOL FOR REMOTE CLASSES IN \\ POSTGRADUATE COURSES
}

\author{
Maria do Carmo Meirelles Toledo CRUZ ${ }^{1}$ \\ Vanda Mendes RIBEIRO ${ }^{2}$ \\ Rafael Lima Medeiros FERREIRA ${ }^{3}$ \\ Simone da Silva RODRIGUES ${ }^{4}$
}

RESUMO: Este artigo visa compartilhar um questionário utilizado para avaliar, por meio das percepções dos discentes, o ensino remoto ofertado no primeiro semestre da pandemia COVID-19, em dois de Programas de Pós-Graduação da área da educação. O questionário foi elaborado com os alunos, para a instituição de um clima favorável à avaliação. Sua versão final, foi disponibilizada por meio do Google Forms, com questões abertas e fechadas, tratando de: (a) caracterização do discente; (b) adesão ao isolamento; (c) infraestrutura da residência; (d) problemas e dificuldades; (e) situações enfrentadas, destacando as de saúde mental e/ou emocionais; e (f) aspectos positivos e a serem aprimorados. O questionário, enviado a 86 alunos, de 26/06/2020 a 12/07/2020, teve adesão de 65\% deles. Os resultados permitiram à universidade a tomada de decisões visando favorecer o ensino e apoiar os alunos.

PALAVRAS-CHAVE: Coronavírus. Pós-graduação. Ensino remoto. Percepção discente. COVID-19.

RESUMEN: Este artículo pretende compartir un cuestionario utilizado para evaluar, a través de las percepciones de los discentes, la enseñanza remota impartida en el primer semestre de la pandemia COVID-19, en dos programas de posgrado del área de educación. El cuestionario se elaboró con los alumnos, para la institución de un clima favorable a la

${ }^{1}$ Universidade Cidade de São Paulo (UNICID), São Paulo - SP - Brasil. Professora do Mestrado Acadêmico em Educação, Professora do Mestrado Profissional em Formação de Gestores Educacionais e Administradora Pública. Doutorado em Administração Pública e Governo (FGV). ORCID: https://orcid.org/0000-0003-43755270. E-mail: carminhameirelles@gmail.com

${ }^{2}$ Universidade Cidade de São Paulo (UNICID), São Paulo - SP - Brasil. Professora do Programa de PósGraduação em Educação e do Programa de Pós-Graduação Formação de Gestores Educacionais. Membro da Rede de Estudos sobre Implementação de Políticas Públicas Educacionais (REIPPE). Doutorado em Educação (USP). ORCID: https://orcid.org/0000-0002-2275-7122. E-mail: vandaribeiro2@gmail.com

${ }^{3}$ Universidade Cidade de São Paulo (UNICID), São Paulo - SP - Brasil. Doutorando no Programa de PósGraduação em Educação. Bolsista CAPES. ORCID: https://orcid.org/0000-0002-6689-0689. E-mail: faelmedeiros.br@gmail.com

${ }^{4}$ Universidade Cidade de São Paulo (UNICID), São Paulo - SP - Brasil. Mestranda no Programa de PósGraduação em Educação. Bolsista CAPES. ORCID: https://orcid.org/0000-0003-1726-3547. E-mail: simonett8173@hotmail.com 
evaluación. Su versión final, se puso a disposición a través de Google Forms, con preguntas abiertas y cerradas, que tratan de: (a) caracterización del estudiante; (b) adhesión al aislamiento; (c) infraestructura de la residencia; (d) problemas y dificultades; (e) situaciones enfrentadas, destacando las de salud mental y/o emocional; y (f) aspectos positivos y a mejorar. El cuestionario, enviado a 86 estudiantes del 26/06/2020 al 12/07/2020, fue respondido por el 65\% de ellos. Los resultados permitieron a la universidad tomar decisiones encaminadas a favorecer la enseñanza y el apoyo a los estudiantes.

PALABRAS CLAVE: Coronavirus. Posgraduación. Enseñanza remota. Percepción del estudiante. COVID-19.

ABSTRACT: This article aims to share a questionnaire used to evaluate, through the perceptions of the students, the remote teaching offered in the first semester of the COVID-19 pandemic, in two of the Postgraduate Programs in the area of education. The questionnaire was prepared with the students, for the institution of a favorable climate for evaluation. Its final version was made available through Google Forms, with open and closed questions, dealing with (a) characterization of the student; (b) adherence to isolation; (c) infrastructure of the residence; (d) problems and difficulties; (e) situations faced, highlighting those of mental health and/or emotional; and (f) positive aspects and to be improved. The questionnaire, sent to 86 students from 06/26/2020 to 07/12/2020, was answered by $65 \%$ of them. The results allowed the university to make decisions aimed at favoring teaching and supporting students.

KEYWORDS: Coronavirus. Postgraduate studies. Remote teaching. Student perception. COVID-19.

\section{Introdução}

Este artigo visa compartilhar um questionário utilizado para avaliar, por meio das percepções dos discentes, o ensino remoto ofertado no primeiro semestre da pandemia COVID-19, em dois de Programas de Pós-Graduação da área da educação. Devido à pandemia do novo coronavírus, muitas organizações precisaram rever e adequar-se a este momento de perigo de contágio e de cuidados com a saúde das pessoas. No âmbito da educação, as instituições de ensino, em todos os seus níveis e etapas, tiveram que se adequar frente à impossibilidade de realizar o ensino presencial (COLEMARX, 2020; LÖWY, 2020). Novos desafios foram colocados às instituições de educação superior (GOMES et al., 2020; PIMENTEL et al., 2020).

Algumas universidades optaram, logo no primeiro semestre de 2020, por se organizarem e adotaram o Ensino Remoto Síncrono Emergencial em seus cursos, conforme afirma Arruda (2020). Para o autor, esse meio se diferencia da educação a distância (EAD) 
porque as aulas são transmitidas "em tempo instantâneo", facilitando as interações entre alunos e professores e permitindo uma organização do tempo que se aproxima mais da modalidade presencial (ARRUDA, 2020, p. 262).

Arruda (2020) afirma, ainda, que as tecnologias de informação e comunicação (TIC) proporcionaram recursos à educação remota permitindo, assim, a continuidade das aulas, evitando que o afastamento dos estudantes das unidades escolares comprometesse a qualidade da educação. Além disso, as TICs foram, segundo o autor, primordiais para preservar a relação entre estudantes, professores e demais profissionais da educação. Entretanto, tal situação não foi sem custos:

\begin{abstract}
Países europeus mais conhecidos, como França, Espanha, Portugal e Inglaterra adotaram estratégias de vínculo escolar por meio da mediação de tecnologias digitais de informação e comunicação. Na grande maioria, os relatos apresentam também dificuldades quanto à gestão e implementação da aprendizagem remota devido a fatores diversos, como dificuldades de alunos e professores acompanharem as aulas, falta de acesso de parcela da população às tecnologias de informação e comunicação. Os relatos demonstram ainda que os governos destes países estabeleceram políticas públicas para maximizar o acesso técnico a equipamentos, de maneira a ampliar a equidade no processo de ensino e aprendizagem (ARRUDA, 2020, p. 260).
\end{abstract}

$\mathrm{O}$ instrumental em tela se consubstancia nesse contexto. Pesquisa na base Scielo, em agosto de 2020, com as palavras-chave "covid" e "pós-graduação" e "Covid" e "educação superior" não identificou artigos. Por meio das palavras "educação" e "Covid" foram identificados 28 trabalhos, concentrados em estudos da área da saúde. Da educação, dois abordavam a educação básica em tempos de pandemia e outros dois, a questão do financiamento relacionando COVID-19 e educação. Com as palavras-chave "Covid" e “education", apareceram 31 trabalhos, três deles tratavam da educação básica e um, do desafio do financiamento das universidades federais em tempos de Covid. Os demais abordavam questões referentes à área da saúde. Não foi identificado, naquele momento, trabalhos no Scielo sobre avaliação do ensino remoto por meio das percepções dos discentes de pós-graduação.

De forma a ampliar a pesquisa, foi realizado levantamento no Google Acadêmico e identificou-se mais de 90 artigos utilizando as palavras-chave "covid" e "pós-graduação"; "percepção discente" e "covid"; e "covid" e "ensino superior". De 90 textos analisados, três trabalhos formam tidos como pertinentes à esta pesquisa, com foco na percepção dos discentes de Pós-graduação sobre o ensino remoto na pandemia: Vercelli (2020); Manhães, Musial e Guindani (2020); e Durso e Russo (2020). 
Vercelli (2020) estuda a percepção dos alunos de um mestrado profissional de educação e destaca aprendizagens obtidas e desafios a serem enfrentados. O uso de tecnologias pelos alunos é uma das maiores dificuldades identificadas. Os alunos destacam como positivo a aprendizagem do uso de diferentes plataformas; a otimização do tempo, em função de não precisarem se deslocar de casa à universidade; boa interação entre professores e alunos e a qualidade das aulas oferecidas. Para a autora, o período de pandemia trouxe desafios e novos olhares que precisam ser pesquisados, para que se identifique as fragilidades do uso do ensino remoto, mas também o que se aprendeu com ele.

Manhães, Musial e Guindani (2020) destacam a percepção dos pós-graduados lato sensu sobre menos justiça acadêmica frente ao uso das TICs na pandemia do que diante do ensino presencial.

Durso e Russo (2020) realizaram uma pesquisa quantitativa e identificaram o nível de satisfação dos discentes em programas de mestrado e doutorado da área de negócios. Para medir o nível de satisfação sobre as adequações dos cursos na pandemia, foi criado o índice de satisfação com as mudanças. Os dados mostraram um nível "moderado" de satisfação. As características pessoais e o contato prévio com cursos de longa duração em educação a distância são fatores significativos nas diferenciações de motivação.

Naquele momento de início da pandemia observou-se um baixo número ainda de artigos na base Scielo, que tratavam de avaliação por meio das percepções dos discentes da pós-graduação brasileira, sobre a introdução do ensino remoto devido à pandemia, compreendendo-o segundo as definições de Arruda (2020). Nenhum deles aportava o instrumento de pesquisa utilizado. Esse artigo visa, oferecer como contribuição um questionário testado em dois Programas de Pós-Graduação considerando ainda que foi útil para a tomada de decisões frente a problemas detectados.

\section{Metodologia}

A ação avaliativa apresentada por este artigo buscou, por meio das percepções dos discentes sobre o ensino remoto adotado durante o primeiro semestre da pandemia COVID19, enfrentar os desafios do campo da avaliação educacional. Segundo a literatura é importante envolver os sujeitos; alcançar simplicidade; conseguir melhorar a vida das instituições e pessoas; levar à negociação e ao estabelecimento de consensos; e ter o processo 
avaliativo legitimado pelos responsáveis pelas decisões (FERNANDES, 2007; FITZPATRICK; CHRISTIE; MARK, 2009).

Considerando os referidos princípios, buscou-se envolver os alunos por meio da construção coletiva do questionário em tela, com o apoio de um grupo de pesquisa da instituição. O primeiro esboço do instrumento, elaborado por professores dos Programas de Pós-Graduação, baseou-se na pesquisa da Universidade Federal de São Carlos (2020) sobre os limites e potencialidades do exercício das atividades escolares remotas na educação básica. $\mathrm{O}$ instrumental foi discutido com os alunos e dois pré-testes com discentes foram realizados, de forma a contribuir para o aprimoramento das questões, para se tornassem simples e de fácil entendimento.

Esse procedimento visou ainda a construção de um clima favorável ao processo avaliativo (SOUZA; GATTI, 2015). O formulário foi disponibilizado por meio do Google forms. Buscando a legitimidade do processo avaliativo, discutiu-se também, sobre a avaliação com os coordenadores dos Programas e professores. Ademais a divulgação foi realizada pelas coordenações dos Programas de Pós-Graduação. Alunos sistematizaram os dados; auxiliaram na análise; e na divulgação dos resultados da pesquisa. A iniciativa foi também apresentada à Pró-Reitoria de Pesquisa da Universidade.

O questionário continha 32 perguntas, das quais 29 fechadas. As questões envolviam: a) caracterização do discente (idade, sexo, raça/cor, renda, bolsistas, deficiência ou mobilidade reduzida, jornada de trabalho, atuação na educação, vínculo profissional); b) adesão ao isolamento na pandemia; c) infraestrutura na residência para a aula remota (local, equipamento, etc.); d) problemas e dificuldades (softwares usados, realização das atividades, etc.); e) situações enfrentadas (gerais, de saúde mental e/ou emocionais, e de familiares com Covid); e f) aspectos positivos e aqueles a serem aprimorados nas aulas remotas.

A versão final do questionário, avaliada e aprovada pelas Coordenações dos dois Programas de Pós-Graduação, dispõe de um Termo de Consentimento Livre e Esclarecido (TCLE) que apresenta os objetivos do estudo e oferece ao participante um campo para optar ou não por responder às perguntas.

O questionário foi disponibilizado de forma eletrônica, via Google Forms, no período de 26/06/2020 a 12/07/2020, a 86 pós-graduandos, assim distribuídos: 52 alunos do curso de Mestrado em Educação; 12 de Doutorado em Educação e 22 de Mestrado em Formação de Gestores Educacionais. Desse universo de 86 investigados, a pesquisa teve adesão de 56 respondentes, o que contabilizou um total de $65 \%$ de retorno do instrumento. 
De acordo com Chaer, Diniz e Ribeiro (2011, p. 261), “deve-se voltar especial atenção à construção das perguntas que comporão [um] questionário, pois é delas que se conseguirá, ou não, obter os corretos dados”. Hill e Hill (1998) destacam o desafio de elaborar um bom questionário. Razão pela qual faz-se relevante compartilhar um instrumento já testado.

Gil (1999) apresenta algumas das vantagens de se utilizar esse tipo de instrumento de pesquisa, dentre elas, cita o menor custo em relação a outros meios, a garantia do anonimato das pessoas, o fato de que, nessa modalidade, o pesquisado escolhe o melhor momento para participar da pesquisa.

Seguem, na íntegra, as questões formuladas para o estudo, de forma que outras instituições possam apropriar-se desse instrumento e da sua forma de elaboração para, em caso de necessidade, adequar e replicar a pesquisa em suas unidades.

\section{O questionário}

\section{Termo de Consentimento Livre e Esclarecido}

Este instrumento se reporta a uma pesquisa realizada pela Coordenação do Programa de Pós-Graduação em Educação (PPGE) e Programa de Pós-Graduação Formação de Gestores Educacionais (PPGP-GE) com o objetivo de identificar como os discentes estão lidando com as atividades acadêmicas durante a pandemia. Dessa forma, solicitamos sua contribuição por meio do preenchimento deste questionário.

Informamos ainda que este questionário poderá ser adaptado e publicizado, por meio de trabalhos de pesquisa, desde que seja reconhecida a fonte e a forma de elaboração. Assim sendo, escolha a opção que melhor representa seu interesse em participar deste estudo:

( ) Conheço o objetivo e desejo participar desta pesquisa.

( ) Não desejo participar desta pesquisa.

\section{Indique seu curso de Pós-Graduação:}

( ) Mestrado Profissional em Formação de Gestores Educacionais

( ) Mestrado Acadêmico em Educação

( ) Doutorado Acadêmico em Educação

\section{2. É bolsista na Pós-Graduação?}
( ) $\mathrm{Sim}$

( ) Não

3. Sexo:

( ) Homem 
( ) Mulher

4. Raça/cor:

( ) Preta

( ) Parda

( ) Branca

( ) Amarela

( ) Indígena

\section{Idade:}

( ) De 20 a 30 anos

( ) De 31 a 40 anos

( ) De 41 a 50 anos

( ) De 51 a 60 anos

( ) Mais de 60 anos

\section{Possui deficiência ou mobilidade reduzida?}
( ) Sim. Se "sim", qual:
( ) Não

\section{Trabalha:}

( ) Menos de 20h semanais

( ) De 20h a $29 \mathrm{~h}$ semanais

( ) De 30 a $39 \mathrm{~h}$ semanais

( ) 40h semanais

( ) Mais de 40h semanais

( ) Não trabalha

\section{Renda familiar:}
( ) Até R\$1.045,00
( ) Entre R\$1.046,00 a R \$2.000,00
( ) Entre R\$2.001,00 a R\$ 5.000,00
( ) Entre R\$ 5.001,00 a R\$ 8.000,00
( ) Mais de $\mathrm{R} \$ 8.000$

\section{Atua na área da Educação?}

( ) Formal (educação no âmbito dos sistemas de ensino)

( ) Não formal (iniciativas de aprendizagem que acontecem fora dos sistemas de ensino)

( ) Não atuo na área da Educação

\section{0. É professor?}

( ) Sim, da rede pública municipal

( ) Sim, da rede pública estadual

( ) Sim, da rede pública federal 
( ) Sim, da rede privada

( ) Sou professor, mas não estou exercendo a função/cargo

( ) Não sou professor

11. Em qual etapa/nível/modalidade de ensino atua? (Pode ser assinalada mais de uma alternativa)

( ) Educação infantil (creche ou pré-escola)

( ) Ensino fundamental I ou II (anos iniciais ou finais

( ) Ensino médio

( ) Educação superior

( ) Educação tecnológica e formação profissional

( ) Educação a distância e tecnologias educacionais

( ) Educação de jovens e adultos

( ) Educação especial

( ) Educação indígena

( ) Educação não formal

( ) Não atuo na área da Educação

12. Está conseguindo cumprir o isolamento social?
() $\mathrm{Sim}$
( ) Não
( ) Parcialmente

13. Quantas pessoas residem na sua moradia?
( ) 1 pessoa
( ) 2 pessoas
( ) 3 pessoas
( ) 4 pessoas
( ) 5 pessoas
( ) Mais de 5 pessoas

14. Em sua residência alguém contraiu o coronavírus?

( ) Sim, sem sintomas

( ) Sim, com sintomas leves

( ) Sim, com sintomas fortes

( ) Sim, com óbito

( ) Não ou não sei

15. Quantos desktop, notebook, laptop e tablet há em sua residência?

( ) 1 equipamento

( ) 2 equipamentos

( ) 3 equipamentos

( ) 4 equipamentos

( ) 5 equipamentos

Temas em Educ. e Saúde, Araraquara, v. 17, n. 00, 021019, 2021. 
( ) Mais de 5 equipamentos

16. Quantos celulares há em sua residência?

( ) 1 equipamento

( ) 2 equipamentos

( ) 3 equipamentos

( ) 4 equipamentos

( ) 5 equipamentos

( ) Mais de 5 equipamentos

17. Qual(is) equipamento(s) foi(ram) utilizado(s) para acesso às aulas? (Pode ser assinalada mais de uma alternativa)
( ) Desktop
( ) Notebook ou Laptop
( ) Tablet
( ) Celular
( ) TV

18. Na sua residência, há acesso à internet?
() $\mathrm{Sim}$
( ) Não

19. Qual sua modalidade de internet? (Pode ser assinalada mais de uma alternativa)
( ) Banda larga
( ) Rádio
( ) Cabo
( ) Telefone
( ) Uso o celular para acessar a internet
() Pen Modem
( ) Box
( ) Outra. Se assinalou "Outra", qual:

20. Qual espaço usou para participar das aulas? (Pode ser assinalada mais de uma alternativa)
( ) Quarto individual
( ) Quarto coletivo
( ) Escritório
( ) Sala ou outro espaço de uso coletivo
( ) Espaço não residencial
( ) Outro. Se assinalou "Outro", qual:

21. O espaço antes descrito permitiu assistir às aulas com conforto acústico?

() $\mathrm{Sim}$

( ) Não 
22. O espaço antes permitiu assistir às aulas com conforto físico?

( ) $\operatorname{Sim}$

( ) Não

23. Você teve problemas com os sistemas/softwares utilizados nas disciplinas? (Pode ser assinalada mais de uma alternativa)

( ) Jitsi

( ) Blackboard

( ) Google meet

( ) Zoom

( ) Cisco webex

( ) WhatsApp

( ) Skype

( ) Hangouts

( ) Não tive problema

24. Qual a dificuldade enfrentada para realizar as atividades da Pós-Graduação? (Pode ser assinalada mais de uma alternativa)

( ) Não tive dificuldade

( ) Concentração

( ) Organização dos estudos

() Falta de apoio dos professores

( ) Sobrecarga com o teletrabalho

() Sobrecarga com as tarefas domésticas

( ) Sobrecarga com trabalhos escolares e aulas dos filhos

( ) Sobrecarga devido aos cuidados com os filhos

( ) Outra. Se assinalou "Outra", qual:

25. Quais problemas foram enfrentados em relação aos equipamentos para assistir às aulas remotas? (Pode ser assinalada mais de uma alternativa)

( ) Não tive problemas para assistir às aulas

( ) Não tenho equipamento adequado para ser utilizado nas aulas

( ) Possuo acesso limitado à internet

( ) Compartilho o equipamento com outros moradores da residência

( ) Na região onde resido a internet é restrita e/ou apresenta falhas constantes

( ) Outro. Se assinalou "Outro", qual?

26. Durante as aulas, com qual frequência teve problemas com a internet?

( ) Não tive problemas com a internet

( ) Em poucas aulas

( ) Em aproximadamente metade das aulas

( ) Em mais da metade das aulas

( ) Em todas as aulas 
27. Quais situações enfrentou durante a pandemia? (Pode ser assinalada mais de uma alternativa)

( ) Não tive problemas

( ) Sobrecarga de tarefas domésticas

( ) Sobrecarga de tarefas profissionais

( ) Necessidade de auxiliar nos trabalhos escolares e aulas dos filhos

( ) Ampliação dos cuidados com os filhos

( ) Outra. Se assinalou "Outra", qual:

28. Quais situações de saúde mental e/ou emocionais enfrentou durante a pandemia? (Pode ser assinalada mais de uma alternativa)
() Tristeza
() Felicidade
( ) Solidão
( ) Sensação de abandono
( ) Sensação de incapacidade ou impotência
( ) Raiva
( ) Insônia
( ) Ansiedade e/ou angústia
( ) Medo de perder o emprego
( ) Medo de contrair o coronavírus
( ) Medo de perder entes familiares
( ) Medo de morrer
( ) Medo de enfrentar uma crise econômica
( ) Luto
( ) Crise de pânico
( ) Depressão
( ) Ideação suicida
( ) Estresse
( ) Outra. Se assinalou "Outra", qual:

29. As disciplinas da Pós-Graduação promoveram: (Pode ser assinalada mais de uma alternativa)

( ) Socialização entre os alunos

( ) Compartilhamento de informações

( ) Realização de trabalhos conjuntos

( ) Acolhimento por parte dos(as) professores(as)

( ) Outra. Se assinalou "Outra", qual:

30. O que foi positivo nas disciplinas ministradas de forma remota no decorrer do $1^{0}$ semestre de 2020? 


\section{O que poderia ser melhorado nas disciplinas ministradas de forma remota no decorrer do $1^{\circ}$ semestre de 2020 ?}

\section{Outros comentários ou sugestões:}

\section{Considerações finais}

Este artigo visa compartilhar um questionário utilizado para avaliar, por meio das percepções dos discentes, o ensino remoto ofertado no primeiro semestre da pandemia COVID-19, em dois de Programas de Pós-Graduação da área da educação. Os resultados da avaliação permitiram à Universidade, na qual estão inseridos os dois Programas de PósGraduação, replicar o questionário entre os estudantes de todos os seus Programas de PósGraduação, visando obter informações que subsidiassem ações de suporte e apoio aos seus discentes e, desse modo, contribuísse para contornar, da melhor maneira possível, os transtornos causados pelas medidas de isolamento social que impediu o ensino presencial.

Seguem algumas decisões tomadas pela universidade com essa finalidade: parceria da universidade para disponibilizar a internet a um preço acessível aos discentes com dificuldade de acesso à rede; articulação da Pós-graduação com o Curso de Psicologia com consequente criação de um Grupo Psicoterapêutico para atendimento dos mestrandos e doutorandos; comunicação por grupos de WhatsApp, por disciplina e por programa; ampliação da prestação de apoio remoto aos estudantes pela biblioteca.

O questionário foi, ainda, utilizado como base para uma pesquisa realizada por uma Escola Técnica do Centro Paula Souza do governo do estado de São Paulo localizada no Município de São Paulo.

Desta forma, com a divulgação do instrumento de pesquisa e dos procedimentos metodológicos adotados, espera-se que outros Programas de Pós-graduação possam utilizar, criticar, aprimorar e disseminar o instrumental aqui apresentado.

AGRADECIMENTOS: Os autores agradecem o grupo de pesquisa Implementação de Políticas Educacionais e Desigualdades da Universidade Cidade de São Paulo e a Coordenação de Aperfeiçoamento de Pessoal de Nível Superior (Capes) pelas bolsas Programa de Suporte à Pós-Graduação de Instituições de Ensino Particulares (Prosup) disponibilizadas aos dois alunos que participaram da pesquisa. Também agradecem as contribuições advindas do I Congresso Internacional de Investigação e Experiência Educativa. 


\section{REFERÊNCIAS}

ARRUDA, E. P. Educação remota emergencial: elementos para políticas públicas na educação brasileira em tempos de Covid-19. Revista de Educação a Distância, Minas Gerais, v. 7, n. 1, 2020.

CHAER, G.; DINIZ, R. R. P.; RIBEIRO, E. A. A técnica do questionário na pesquisa educacional. Evidência, Araxá, v. 7, n. 7, p. 251-266, 2011.

COLEMARX. COLETIVO DE ESTUDOS EM MARXISMO E EDUCAÇÃO. Em defesa da educação pública comprometida com a igualdade social: porque os trabalhadores não devem aceitar aulas remotas. Rio de Janeiro: UFRJ, 2020. Disponível em:

http://www.colemarx.com.br/wpcontent/uploads/2020/04/Colemarx-texto-cr\%C3\%ADticoEaD-2.pdf. Acesso em: 03 set. 2020.

DURSO, S. O.; RUSSO, P. T. Impactos da Covid- 19 em programas stricto sensu da área de negócios: possibilidades para o ensino à distância? In: USP INTERNACIONAL

CONFERENCE IN ACCOUNTING: ACCOUNTING AS A GOVERNANCE MECHANISM, 20., 2020, São Paulo. Anais [...]. São Paulo, SP: USP,2020. p. 1-5.

FERNANDES, D. Limitações e potencialidades da avaliação educacional. Lisboa, 2007.

FITZPATRICK, J.; CHRISTIE, C.; MARK, M. M. Evaluation in action: Interviews with expert evaluators. London: Sage, 2009.

GIL, A. C. Métodos e técnicas de pesquisa social. 5. ed. São Paulo: Atlas, 1999.

GOMES, V. T. S. et al. A pandemia da covid-19: repercussões do ensino remoto na formação médica. Rev. bras. educ. med., Brasília, v. 44, n. 4, e114, 2020.

HILL, M. M.; HILL, A. B. A construção de um questionário. Lisboa: Dinâmica, 1998.

JOYE, C. R.; MOREIRA, M. M.; ROCHA, S. S. D. Distance Education or Emergency Remote Educational Activity: in search of the missing link of school education in times of COVID-19. Research, Society and Development, v. 9, n. 7, p. 1-29, e521974299, 2020.

LÖWY, M. “Gripezinha” o neofascista Bolsonaro diante da epidemia. In: Quarentena: reflexões sobre a pandemia e depois. 1. ed. Bauru: Canal 6,2020. p. 147-151.

MANHÃES, F.; MUSIAL, N. T. K.; GUINDANI, R. A. Do ensino presencial ao EAD: Um estudo sobre percepção de justiça acadêmica durante a pandemia do COVID-19. In:

CONGRESSO UFSC DE CONTROLADORIA E FINANÇAS, 10., 2020, Florianópolis. Anais [...]. Florianópolis, SC: UFSC, 2020. p. 1-12.

PIMENTEL, F. S. C. et al. Atividades na pós-graduação utilizando as ferramentas digitais no contexto da crise da covid 19: análise qualitativa descritiva. Em Rede, Porto Alegre, v. 7, n. 1, p. 276-293, 2020.

SOUZA, C.; GATTI, B. Avaliação de instituição de ensino superior e autoavaliação educacional. Instituto Nacional de Estudos e Pesquisas Educacionais Anísio Teixeira (Brasil). 
In: SEMINÁRIOS REGIONAIS SOBRE AUTOAVALIAÇÃO INSTITUCIONAL E COMISSÕES PRÓPRIAS DE AVALIAÇÃO (CPA), 2015, Brasília. Anais [...]. Organizado por Claudia Maffini Griboski e Stela Maria Meneghel. Brasília, DF: Inep, 2015. p. 30-37.

UNIVERSIDADE FEDERAL DE SÃO CARLOS (UFSCAR). Programa de Pós-Graduação em Educação (campus Sorocaba). Relatório técnico-científico de pesquisa: Condições e dinâmica cotidiana e educativa na RMS (Região Metropolitana de Sorocaba/SP) durante o afastamento social provocado pelo coronavírus. Sorocaba, maio 2020.

VERCELLI, L. C. A. Aulas remotas em tempos de Covid-19: a percepção de discentes de um programa de mestrado profissional em educação. Revista @mbienteeducação, São Paulo, v. 13, n. 2, p. 47-60, maio/ago. 2020.

\section{Como referenciar este artigo}

CRUZ, M. C. M. T.; RIBEIRO, V. M.; FERREIRA, R. L. M.; RODRIGUES, S. S. Socializando um instrumento de autoavaliação de aulas remotas na pós-graduação. Temas em Educ. e Saúde, Araraquara, v. 17, n. 00, 021019, 2021. e-ISSN 2526-3471. DOI: https://doi.org/10.26673/tes.v17i00.15548

Submetido em: 01/08/2021

Aprovado em: 26/09/2021

Publicado em: 03/10/2021 